\title{
Attitudes and Beliefs About Medical Usefulness and Legalization of Marijuana among Cancer Patients in a Legalized and a Nonlegalized State
}

\author{
Kimberson Tanco, MD, ${ }^{1, *}$ Donato Dumlao, MD, ${ }^{2, *}$ Rebecca Kreis, RN, MSN, GNP:BC, ${ }^{2}$ \\ Kristy Nguyen, PharmD, BCPS, ${ }^{3}$ Seyedeh Dibaj, PhD, ${ }^{4}$ Diane Liu, MS, ${ }^{4}$ Vidyasagargoud Marupakula, MD, ${ }^{5}$ \\ Ayesha Shaikh, $\mathrm{MD}^{2}$, Walter Baile, $\mathrm{MD}^{6},{ }^{6}$ and Eduardo Bruera, $\mathrm{MD}^{1}$
}

\begin{abstract}
Background: There is a growing preference for the use of marijuana for medical purposes, despite limited evidence regarding its benefits and potential safety risks. Legalization status may play a role in the attitudes and preferences toward medical marijuana (MM).

Objectives: The attitudes and beliefs of cancer patients in a legalized (Arizona) versus nonlegalized state (Texas) regarding medical and recreational legalization and medical usefulness of marijuana were compared. Settings/Subjects: Two hundred adult cancer patients were enrolled from outpatient Palliative Care centers at Banner MD Anderson Cancer Center in Gilbert, AZ $(n=100)$ and The University of Texas MD Anderson Cancer Center in Houston, TX $(n=100)$.

Design and Measurements: Adult cancer patients seen by the Palliative Care teams in the outpatient centers were evaluated. Various physical and psychosocial assessments were conducted, including a survey of attitudes and beliefs toward marijuana.

Results: The majority of individuals support legalization of marijuana for medical use (Arizona 92\% [85-97\%] vs. Texas 90\% [82-95\%]; $p=0.81$ ) and belief in its medical usefulness (Arizona 97\% [92-99\%] vs. Texas 93\% [86-97\%]; $p=0.33$ ) in both states. Overall, $181(91 \%)$ patients supported legalization for medical purposes whereas $80(40 \%)$ supported it for recreational purposes $(p<0.0001)$. Patients preferred marijuana over current standard treatments for anxiety $(60 \%$ [51-68\%]; $p=0.003)$. Patients found to favor legalizing MM were younger $(p=0.027)$, had worse fatigue $(p=0.015)$, appetite $(p=0.004)$, anxiety $(p=0.017)$, and were Cut Down, Annoyed, Guilty, and Eye Opener-Adapted to Include Drugs (CAGE-AID) positive for alcohol/drugs $(p<0.0001)$. Conclusion: Cancer patients from both legalized and nonlegalized states supported legalization of marijuana for medical purposes and believed in its medical use. The support for legalization for medical use was significantly higher than for recreational use in both states.
\end{abstract}

Keywords: legalization; marijuana; medical marijuana; recreational marijuana; symptom control

\section{Introduction}

$\mathbf{M}$ ARIJUANA is the mixture of parts from the Cannabis plant, including its leaves, stems, seeds, and flowers. ${ }^{1}$ The main active ingredients of the marijuana plant come from compounds known as cannabinoids, which activate specific re- ceptors throughout the body, including the central nervous system and immune system. Although delta-9-tetrahydrocannabinol (THC) is the primary psychoactive ingredient among cannabinoids, there are other compounds with biologic activity, including cannabidiol (CBD), cannabinol, cannabichromene, cannbigerol, tetrahydrocannabivarin, and delta-8-THC.

\footnotetext{
${ }^{1}$ Department of Palliative, Rehabilitation, and Integrative Medicine, University of Texas MD Anderson Cancer Center, Houston, Texas.

${ }^{2}$ Subspecialty Palliative Care in Medical Oncology, Banner MD Anderson Cancer Center, Gilbert, Arizona.

Departments of ${ }^{3}$ Pharmacy and ${ }^{4}$ Biostatistics, University of Texas MD Anderson Cancer Center, Houston, Texas.

${ }^{5}$ Department of Internal Medicine, Banner Gateway Medical Center, Gilbert, Arizona.

${ }^{6}$ Department of Behavioral Science, University of Texas MD Anderson Cancer Center, Houston, Texas.

*Both authors contributed equally.

Accepted June 17, 2019.
} 
Compared with THC, CBD has been considered as having analgesic, anti-inflammatory, and anxiolytic properties while not demonstrating psychoactivity compared with THC. ${ }^{2}$

Marijuana is one of the most commonly used recreational drugs in the United States and is being used more often while also being perceived as less harmful by many Americans. ${ }^{3,4}$ In a cross-sectional national survey from 2002 to 2014 of 596,500 individuals aged 12 or older, marijuana use increased from $10.4 \%$ to $13.3 \%$. On the other hand, the perception of risk of harm from smoking marijuana once or twice a week decreased from $50.4 \%$ to $33.3 \%$. Marijuana use disorders remained stable at $\sim 1.5 \%$ in this period. ${ }^{5}$ This trend follows an inverse association between use and risk perceptions as well as state legalizations laws. ${ }^{6}$ As of 2019 , 33 states in the United States and Washington, DC have voted on various levels of legalization of the marijuana plant for medical purposes, in addition to 17 states allowing the use of CBD extract with minimal THC for treatment of epilepsy., The potential benefits of marijuana have been medically proposed to include antiemetic effects, appetite stimulation, cancer treatment, sleep improvement, and pain relief. ${ }^{2,9-11}$ However, the medical literature and recommendations for use have been disproportionate to the growing support of its potential uses and benefits in the general public. ${ }^{12-15}$

Although some studies have evaluated the perceptions and attitudes of patients regarding the use of medical marijuana (MM) for various health conditions, there are limited data comparing perceptions of its medicinal use in the cancer population, particularly between patients in legalized and nonlegalized states. ${ }^{16-21}$ In a survey of adult cancer patients in a cancer center in a legalized medical and recreational marijuana state, $>20 \%$ of respondents considered themselves active marijuana users and used it for pain, nausea, and stress. Legalization was also found to support the likelihood of use of marijuana. ${ }^{22}$

The U.S. Food and Drug Administration (FDA) has approved dronabinol, nabilone, and epidiolex for various medical purposes but not any other marijuana plant products. In this study, we focused on the perception of marijuana plant products and not these FDA-approved products. Our primary objective was to compare the proportion of cancer patients who have a positive attitude about legalizing marijuana for medical purposes between those in a legalized and a nonlegalized state. Secondary objectives included evaluating the association of cancer patients' belief in the usefulness of marijuana for medical purposes in their state of residency (Arizona [legalized] vs. Texas [nonlegalized]); examining the association of demographic, physical, and psychosocial characteristics of patients and their perception of MM; examining the preference of patients for treatment of pain, anxiety, and depression between MM versus opioids, antianxiety and antidepressant medications; examining the association of media to perception of the use of MM; and evaluating the association of cancer patients' attitude about legalizing marijuana for medical purposes versus recreational purposes. By comparing sites from a legalized and a nonlegalized state, we are able to examine whether legalization status is associated with the attitudes and beliefs of MM by patients. Further, by evaluating patient perception for medical versus recreational purposes, this can help us understand whether patients would prefer to use marijuana for therapeutic reasons alone or for coping and other psychosocial reasons.

\section{Materials and Methods}

The Institutional Review Boards of The University of Texas MD Anderson Cancer Center (MDA Houston) and Banner MD Anderson Cancer Center (MDA Banner) approved this study, and all patients provided written consent.

\section{Patient population}

Adult cancer patients seen by the Palliative Care teams in the outpatient centers at MDA Banner and MDA Houston were evaluated for eligibility to the study. Arizona is a legalized state since 2010 for marijuana for medical use for certain approved conditions, including cancer treatment, cachexia, post-traumatic stress disorder, chronic pain, severe nausea, and severe persistent muscle spasms. ${ }^{23}$ On the other hand, marijuana is not legal in Texas except for treatment of intractable epilepsy by using low-THC cannabis products under the Texas Compassionate Use Act, enacted in $2015^{8}$ Both institutions are cancer centers and the Palliative Care teams in both places see predominantly cancer patients. Due to the sensitivity of information regarding marijuana use, particularly in a nonlegalized state, no identifiers were associated with data recorded. Patients were included if they were able to speak and read English, had a cancer diagnosis, and were residents of the state where the site is located (e.g., if a patient is enrolled at MDA Houston, they should be a resident of the state of Texas). Patients were excluded if they had impaired cognition as determined by the interviewer based on the ability to understand the nature of the study and consent process. In all cases, patients received similar care, regardless of location, by the Palliative Care interdisciplinary team.

\section{Data collection}

The following patient data were collected via self-report and review of clinical records: demographics including gender, age, ethnicity, marital status, education level, religion, cancer diagnosis, past medical conditions, history of past use of tobacco, alcohol, and illicit drugs; alcohol and drugs use screening tool (Cut Down, Annoyed, Guilty, Eye Opener-Adapted to Include Drugs [CAGE-AID]); symptom distress scores using the Edmonton Symptom Assessment System-Financial Spiritual (ESAS-FS); Trust in Medical Profession questionnaire; Hospital Anxiety and Depression Scale (HADS); Santa Clara Strength of Religious Faith questionnaire; and the marijuana survey. These measures are described next.

(1) CAGE-AID Questionnaire ${ }^{24-26}$ : The CAGE questionnaire is a four-item screening tool for alcoholism and it suggests the possibility of an increased risk of maladaptive behavior when there is an exaggerated and inappropriate request for opioid medication. It is an acronym that represents questions about a patient's perceived need to cut down on alcohol use, annoyance with questions about alcohol abuse, guilt over drinking habits, and use of eye-opener drinks. A variation of the CAGE questionnaire is the CAGE-AID, which substituted "drink" with "drink or drugs". For this study, we considered a patient as CAGE+ when they answered "Yes" to at least one item on the CAGE-AID questionnaire.

(2) ESAS-FS ${ }^{27-29}$ : The ESAS is a widely used and validated self-administered measure assessing symptoms on a visual analogue scale of $0-10$, with higher scores indicating 
worse symptom burden. In this study, we used a 12-item version of the ESAS that was developed by the MD Anderson Cancer Center Department of Palliative Medicine, which included nonvalidated items, spiritual pain, and financial distress. This version is regularly used in the inpatient and outpatient area by the Palliative Care team. Symptoms measured include pain, fatigue, nausea, anxiety, depression, drowsiness, anorexia, shortness of breath, insomnia, wellbeing, financial distress, and spiritual pain.

(3) Trust in Medical Profession ${ }^{30}$ : A 5-item scale with an internal consistency of $\alpha=0.87$ was developed as an abbre- viated instrument to measure trust as a key element in a therapeutic relationship. Total sum of responses are scored on a 5-25 scale, with higher values indicating more trust.

(4) HADS $^{31}$ : The HADS is a 14-item self-administered scale separated between anxiety and depression subscales and designed to measure psychological distress primarily in nonpsychiatric populations. Internal consistency showed Spearman correlations of $r=0.70$ for depression and $r=0.74$ for anxiety. Scores range from 0 to 21 for each subscale, with cutoff scores greater than 7 indicating clinically significant symptoms.

Table 1. Patient Demographics and Clinical Characteristics $(N=200)$

\begin{tabular}{|c|c|c|c|c|}
\hline & Arizona & Texas & Overall & $\mathrm{p}$ \\
\hline$n(\%)$ & $100(50.0)$ & $100(50.0)$ & $200(100)$ & \\
\hline $\begin{array}{l}\text { Age } \\
\text { Median (IQR) }\end{array}$ & $61(53-63)$ & $56(47-66)$ & $59(49-68)$ & 0.034 \\
\hline $\begin{array}{l}\text { Gender } \\
\text { Female }\end{array}$ & $51(51 \%)$ & $64(64 \%)$ & $115(57.5 \%)$ & 0.063 \\
\hline $\begin{array}{l}\text { Race, } n(\%) \\
\text { White or Caucasian } \\
\text { Black or African American } \\
\text { Hispanic } \\
\text { Asian }\end{array}$ & $\begin{aligned} 93 & (93) \\
3 & (3) \\
3 & (3) \\
1 & (1)\end{aligned}$ & $\begin{array}{l}65(65) \\
18(18) \\
14(14) \\
3(3)\end{array}$ & $\begin{aligned} 158 & (79) \\
21 & (10.5) \\
17 & (8.5) \\
4 & (2)\end{aligned}$ & $<0.001$ \\
\hline $\begin{array}{l}\text { Marital status, } n(\%) \\
\text { Married } \\
\text { Not married }\end{array}$ & $\begin{array}{l}69(69) \\
31(31)\end{array}$ & $\begin{array}{l}61(61.0) \\
39(39)\end{array}$ & $\begin{array}{r}130(65) \\
70(35)\end{array}$ & 0.113 \\
\hline $\begin{array}{l}\text { Education, } n(\%) \\
\text { Less than college } \\
\text { Completed college and above }\end{array}$ & $\begin{array}{l}58(58.0) \\
42(42)\end{array}$ & $\begin{array}{l}66(66.0) \\
34(34)\end{array}$ & $\begin{array}{r}124(62) \\
76(38)\end{array}$ & 0.009 \\
\hline $\begin{array}{l}\text { Religion, } n(\%) \\
\text { Catholic/Christian } \\
\text { Others }\end{array}$ & $\begin{array}{l}64(64) \\
36(36)\end{array}$ & $\begin{array}{l}82(82) \\
18(18)\end{array}$ & $\begin{array}{r}146(73) \\
54(27)\end{array}$ & 0.003 \\
\hline $\begin{array}{l}\text { Cancer diagnosis, } n(\%) \\
\text { Breast } \\
\text { Gastrointestinal } \\
\text { Genitourinary } \\
\text { GYN } \\
\text { Head and neck } \\
\text { Hematological } \\
\text { Lung } \\
\text { Others }\end{array}$ & $\begin{array}{l}20(20) \\
14(14) \\
16(16) \\
1(1) \\
10(10) \\
9(9) \\
17(17) \\
13(13)\end{array}$ & $\begin{array}{l}21(21) \\
13(13) \\
14(14) \\
10(10) \\
12(12) \\
4(4) \\
12(12) \\
14(14)\end{array}$ & $\begin{array}{l}41(20.5) \\
27(13.5) \\
30(15) \\
11(5.5) \\
22(11) \\
13(6.5) \\
29(14.5) \\
27(13.5)\end{array}$ & 0.221 \\
\hline $\begin{array}{l}\text { CAGE positive, } n(\%) \\
\text { Median ESAS pain, median (IQR) } \\
\text { Median ESAS fatigue, median (IQR) } \\
\text { Median ESAS nausea, median (IQR) } \\
\text { Median ESAS depression, median (IQR) } \\
\text { Median ESAS anxiety, median (IQR) } \\
\text { Median ESAS drowsiness, median (IQR) } \\
\text { Median ESAS shortness of breath, median (IQR) } \\
\text { Median ESAS appetite, median (IQR) } \\
\text { Median ESAS sleep, median (IQR) } \\
\text { Median ESAS well-being, median (IQR) } \\
\text { Median ESAS financial distress, median (IQR) } \\
\text { Median ESAS spiritual pain, median (IQR) } \\
\text { Median trust in medical profession total, median (IQR) } \\
\text { Median Santa Clara Strength of Religious Faith, median (IQR) } \\
\text { Median HADS anxiety, median (IQR) } \\
\text { Median HADS depression, median (IQR) }\end{array}$ & $\begin{array}{l}4(4) \\
5(3-7.5) \\
5(3-7) \\
1(0-3) \\
2(0-5) \\
2(0-5) \\
3(0-5) \\
1(0-4) \\
4(1-5) \\
5(3-7) \\
4(2-5) \\
3.5(1-6.5) \\
1(0-3) \\
12(5-24) \\
32(10-40) \\
7(4-10) \\
6(4-9)\end{array}$ & $\begin{aligned} 22 & (22) \\
4 & (2-6) \\
4 & (3-6) \\
0 & (0-2) \\
1 & (0-4) \\
2 & (0-5) \\
2 & (0-4) \\
0 & (0-3) \\
3 & (0-5) \\
3 & (2-5) \\
3 & (1-5) \\
1 & (0-6) \\
0 & (0-1) \\
12 & (5-21) \\
39 & (10-40) \\
6 & (3-9) \\
6 & (3-7)\end{aligned}$ & $\begin{aligned} & 26(13) \\
& 4(3-7) \\
& 5(3-7) \\
& 1(0-3) \\
& 2(0-4) \\
& 2(0-5) \\
& 2(0-4) \\
& 1(0-3) \\
& 3(0-5) \\
& 4(2-6) \\
& 4(2-5) \\
& 3(0-6) \\
& 0(0-2) \\
& 12(5-24) \\
& 36(10-40) \\
& 7(3-9) \\
& 6(3-8)\end{aligned}$ & $\begin{array}{r}<0.001 \\
0.041 \\
0.140 \\
0.032 \\
0.020 \\
0.381 \\
0.245 \\
0.121 \\
0.039 \\
0.009 \\
0.381 \\
0.009 \\
0.008 \\
0.839 \\
<0.001 \\
0.184 \\
0.036\end{array}$ \\
\hline
\end{tabular}

CAGE, Cut-down, Annoyed, Guilty, Eye-Opener; ESAS, Edmonton Symptom Assessment System; GYN, gynecological; HADS, Hospital Anxiety and Depression Scale; IQR, interquartile range. 
(5) Santa Clara Strength of Religious Faith Questionnaire ${ }^{32-34}$ This is a 10-item measure of strength of religious faith. It has displayed convergent validity and internal consistency of $0.95-0.97$ and test-retest reliability of $0.82-0.93$ in a study on breast cancer patients and healthy young adults. Scores range from 10 (low faith) to 40 (high faith).

(6) Marijuana Surveys for Patients (Supplementary Appendix A) ${ }^{19,35-43}$ : This survey was designed for this study by the authors to determine different aspects of attitudes and beliefs of patients toward MM. Items were adapted from previously published MM and substance abuse surveys, including the WHO Alcohol, Smoking and Substance Involvement Screening Test and the National Drug and Alcohol Research Centre at the University of New South Wales. There have been no validated surveys found on the attitudes and beliefs of cancer patients toward MM. As there are limited studies on MM use in cancer patients, we also adapted items from studies and questionnaires of opioid attitudes, knowledge, and beliefs. Further, the various benefits, indications, and adverse effects of MM in the survey were all adapted from multiple studies as well as from the National Cancer Institute. Items were rated on a five-point Likert scale, except certain items that required more specific choices, including questions on duration, conditions used for, and follow-up questions to certain answers.

\section{Statistical analysis}

One hundred cancer patients from each center were enrolled to provide a $91 \%$ and $88 \%$ power to detect a difference between $75 \%$ versus $55 \%$ and between $65 \%$ versus $45 \%$, respectively. Descriptive statistics such as mean, median, standard deviation, and range for continuous variables and frequency and proportion for categorical variables were utilized to summarize the data. The distribution of these variables was compared between the two states by Fisher's exact test, McNemar's test, and Wilcoxon rank-sum test for categorical and continuous variables. Ninety-five percent ClopperPearson confidence interval was presented for proportions.

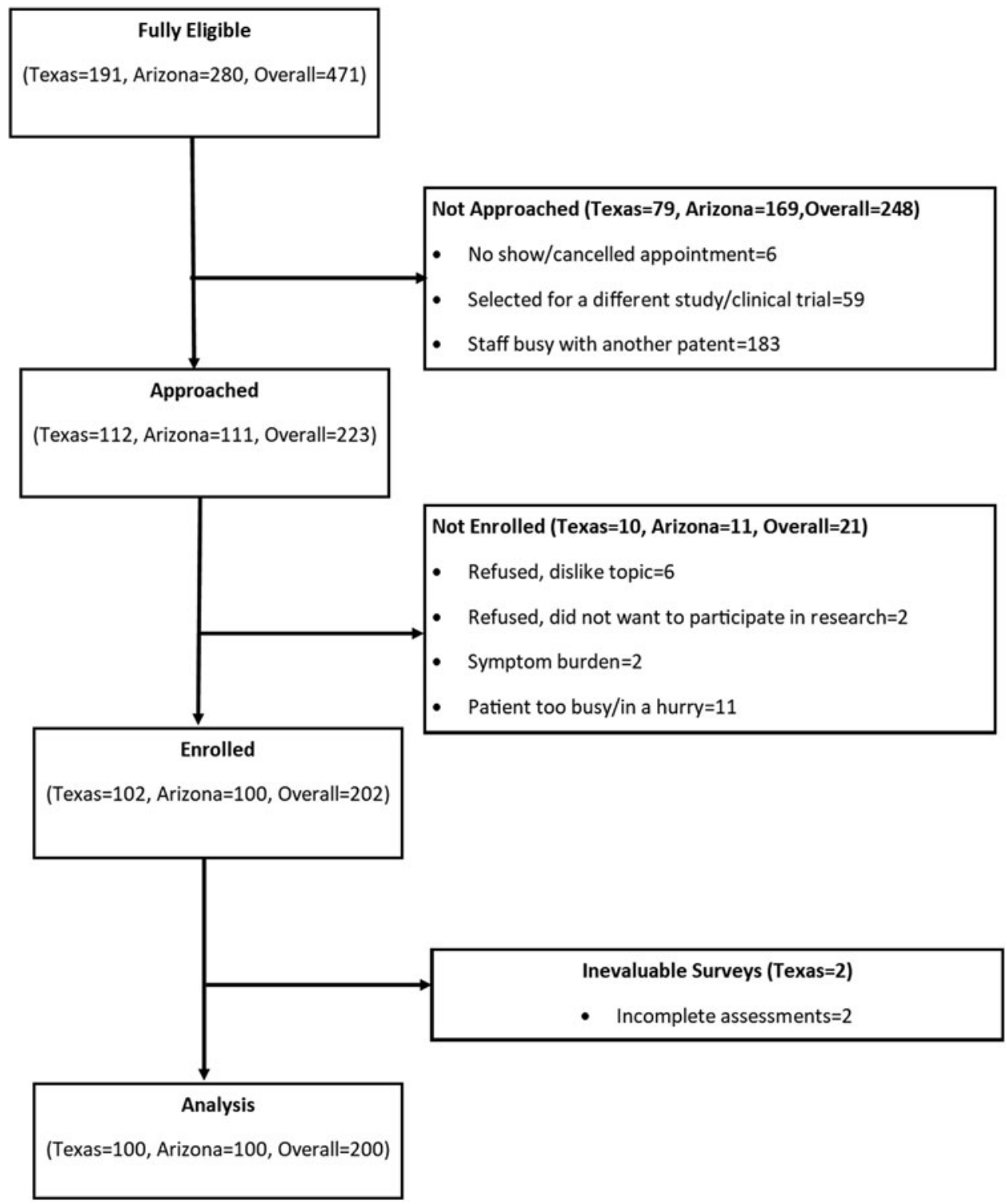

FIG. 1. CONSORT diagram. 
Table 2. Attitudes and Beliefs of Patients TOWARD Medical MariJuana

\begin{tabular}{|c|c|c|c|}
\hline Site & Agree, n (\%) & $\begin{array}{l}\text { Difference in } \\
\text { agreement ( } 95 \% \text { CLI) }\end{array}$ & $\mathrm{p}$ \\
\hline \multicolumn{4}{|c|}{ I. Legalize medical marijuana } \\
\hline Arizona & $91(92)$ & $1.9 \%(-11.8 \%$ to $15.8 \%)$ & 0.81 \\
\hline Texas & $90(90)$ & & \\
\hline Total & $181(91 \%)$ & & \\
\hline \multicolumn{4}{|c|}{ II. Medical marijuana usefulness } \\
\hline Arizona & $97(97)$ & $4 \%(-10.3 \%$ to $18.2 \%)$ & 0.33 \\
\hline Texas & $93(93)$ & & \\
\hline Total & $190(95 \%)$ & & \\
\hline
\end{tabular}

\section{Results}

Two hundred patients were enrolled between December, 2017 and April, 2018 at the outpatient Palliative Care centers in Banner MD Anderson and MD Anderson Houston. Patient characteristics are summarized in Table 1. Two patients were not evaluable due to incomplete assessments and were replaced (Fig. 1). Median age was 59 years and 58\% were female. Fifty five percent of patients from Arizona and 66\% from Texas had never used marijuana for any reason.

\section{Primary outcome}

There was no significant difference in the proportion of patients between the two states who expressed support on legalization of marijuana for medical use (Table 2). When patients from both states were combined, $91 \%$ agreed that marijuana should be legal for medical purposes.

\section{Secondary outcomes}

There was no significant difference in the proportion of patients who believe in the usefulness of marijuana medically (Table 2). With patients from both states combined, 95\% believed that marijuana can be useful for medical reasons, including for pain, nausea, sleep, and appetite stimulation. Fifty four percent and 55\% of patients from Arizona and Texas, respectively, expressed no concerns regarding the safety of MM.

Table 3 shows demographic, physical, and psychosocial factors that show significant association in patients' attitudes in support of MM legalization. There was no significant association found with other demographic, physical, or psychosocial characteristics, including gender, race, trust, anxiety, depression, and religiosity, and previous marijuana use.

As compared with the expected 50\% distribution, significant difference was seen in preference of MM over anti-anxiety medications $(p=0.003)$ but not over pain medications and antidepressants. On evaluating the association of media to patients' perception of MM use, 66 out of 197 (34\%) patients felt that media had affected their perception of marijuana use.

Table 4 shows attitudes about legalizing marijuana for medical versus recreational purposes. There was a significant difference in the proportion of patients who had a positive attitude about legalizing marijuana for medical purposes compared with recreational purposes in the overall popula-
Table 3. Association Between Physical and Psychosocial Characteristics aNd AtTITUdes toward Medical Marijuana Legalization

\begin{tabular}{lccc}
\hline & $\begin{array}{c}\text { Supporting } \\
\text { legalization }\end{array}$ & $\begin{array}{c}\text { Nupporting } \\
\text { legalization }\end{array}$ & $\mathrm{p}$ \\
\hline $\begin{array}{l}\text { Age, median (IQR) } \\
\text { ESAS-FS fatigue, } \\
\text { median (IQR) }\end{array}$ & $59(48-67)$ & $67(56-72)$ & 0.027 \\
$\begin{array}{c}\text { ESAS-FS appetite, } \\
\text { median (IQR) }\end{array}$ & $3(1-5)$ & $0.5(1-5)$ & 0.015 \\
$\begin{array}{c}\text { HADS anxiety, } \\
\text { median (IQR) }\end{array}$ & $7(4-9)$ & $4(1-7)$ & 0.004 \\
$\begin{array}{c}\text { CAGE-AID, } n / n \\
\text { lagede }\end{array}$ & $26 / 181$ & $0 / 18$ & $<0.0001$ \\
\hline
\end{tabular}

CAGE-AID, Cut Down, Annoyed, Guilty, Eye Opener-Adapted to Include Drugs; ESAS-FS, Edmonton Symptom Assessment System-Financial Spiritual.

tion $(p<0.0001)$, in Arizona $(p<0.0001)$ and in Texas $(p<0.0001)$. In the overall group, patients who supported recreational marijuana were also found to be more likely to support MM (96\% vs. $87 \%, p=0.022)$.

\section{Discussion}

To our knowledge, this is the first study that directly compared cancer patients' perception of MM in a legalized state versus a nonlegalized state. In this study, the vast majority of patients from both states agreed about legalizing marijuana for medical use and its medical usefulness. Our findings reflect a paradox of strong preference for medical use of marijuana by patients, which is not accompanied by a high level of evidence in the medical literature for any of the patient-endorsed symptoms. ${ }^{12-15}$ In our study, patients supported the use of marijuana for pain, anxiety, and depression, and they significantly preferred it over antianxiety medications. They also believed that it can be useful for nausea, sleep, and appetite stimulation. These beliefs were shared by patients in both states, even though the palliative care providers seeing them did not recommend MM. These reflect similar findings published regarding patients' reasons for marijuana use. ${ }^{22,44}$ Our study also found that there was a trend for increased support in those who are younger and with worse symptoms, including appetite, fatigue, and anxiety. These findings suggest that patients who are more symptomatic might be more likely to seek alternative interventions such as marijuana in an attempt to seek relief.

In a recently published prospective cohort study of head and neck cancer patients, patients using marijuana weekly reported lower levels of patient-reported anxiety/depression

Table 4. Attitudes of Legalizing Marijuana for Medical versus Recreational Purposes

\begin{tabular}{lccc}
\hline & Medical, $\mathrm{n}(\%)$ & Recreational, $\mathrm{n}(\%)$ & $\mathrm{p}$ \\
\hline Arizona & $91(92)$ & $43(43)$ & $<0.0001$ \\
Texas & $90(90)$ & $37(37)$ & $<0.0001$ \\
Overall & $181(91)$ & $80(40)$ & $<0.0001$ \\
\hline
\end{tabular}


and pain/discomfort, as well as better well-being. ${ }^{45}$ On the other hand, in a prospective national cohort of patients with chronic noncancer pain, patients who used cannabis had greater pain severity and anxiety scores after 4 years. ${ }^{46}$ In a review of cannabinoids for symptom management, cannabinoids were found to result in a modest reduction of cancer pain but not better for chemotherapy-induced nausea and vomiting than olanzapine and neurokinin-1 antagonists. In addition, immunosuppressed patients are at risk for potential infections, particularly in those who smoke cannabis. ${ }^{14}$

An important consideration is that patients may be taking cannabinoids with other medications such as opioids, anxiolytics, antidepressants, and anticholinergics, which may lead to potentially serious interactions and should be discussed as an important element of safety. ${ }^{44}$ Our findings showed that $>50 \%$ of patients were not concerned about safety of MM. This is similar to a survey of medical oncologists who perceived that MM had a lower risk than opioids for addiction, overdose, and death, with $46 \%$ recommending marijuana for clinical use. ${ }^{47}$ There is limited evidence on the efficacy and toxicities of a combination of marijuana with opioids and other medications, particularly in vulnerable patient populations. More research is needed to understand the role of marijuana for medical purposes as continued interest from patients and families for medical use of marijuana will continue to be elevated in both legal and nonlegal states.

An existing argument is that MM may be helpful to reduce opioid prescriptions and opioid overdose-related mortality. ${ }^{48-51}$ Although the majority of patients perceived marijuana as medically useful, the evidence is mixed regarding the effect of MM legalization in association with opioid prescription and use. Data on Medicaid State Drug Utilization Data (1993-2014) showed an association of MM legalization to reduction in Schedule III opioid prescriptions and dosages but not with Schedule II opioids. ${ }^{52}$ In participants with chronic noncancer pain who were followed for 4 years, there was no evidence that cannabis use was associated with a reduction in opioid use or discontinuing opioids. ${ }^{46}$ In addition, in a study of patients who underwent weight reduction surgeries, patients who reported marijuana use were found to have higher perioperative opioid requirements despite lower subjective pain scores. ${ }^{53}$ In contrast, recent data on Medicaid (2011-2016) and Medicare Part D (2010-2015) enrollees exhibited a decrease in opioid prescribing rates in states that legalized marijuana use, and Medicaid data (2007-2014) showed less prescriptions for depression, nausea, psychosis, and seizure medications. ${ }^{48-50}$ However, Powell et al. reported factors that may reduce the reported impact of marijuana on opioid prescription and deaths, including stricter state laws on dispensaries in providing marijuana products, properly quantifying deaths between natural/semisynthetic opioids versus synthetic opioids and heroin, and characterizing opioid misuse between medical and nonmedical reasons. ${ }^{51}$ Further long-term studies are needed to evaluate the effect of MM on opioid prescriptions, use, and mortalities.

An interesting finding was that the majority of patients from both states have never used marijuana medically but still preferred legalization of MM, which may reflect the growing positive acceptance of MM in society and belief in its potential medical benefits. These results are also consistent with the increasing number of patient inquiries about using this substance. In a recent national survey of adults aged $>18$ years,
$10.5 \%$ respondents reported using marijuana for medical use, $53.4 \%$ for recreational use, and $36.1 \%$ for both medical and recreational use. ${ }^{54}$ In contrast, the majority of our cancer patients had a positive attitude toward legalizing marijuana for medical use but not for recreational use, which is similar to findings by Pergam et al. ${ }^{22}$ This may reflect patient preferences of having a therapeutic indication and purpose before using a product rather than for coping alone, which is reflected in findings from a study on cancer patients undergoing chemotherapy. ${ }^{44}$ On the other hand, this also points to the increasing belief of its medical usefulness from patients and families, even if the medical evidence is not yet robust. Our study is not able to identify factors that favor patients to have a more positive attitude toward medical use compared with recreational use. More research is necessary to understand factors that affect patient perception of marijuana medically over recreationally.

Although this study focused on comparing attitudes and beliefs of the use of marijuana in a legalized versus a nonlegalized state, a limitation of the study was that it measured these aspects in a limited geographical area. A variety of political, cultural, and religious factors in other states or countries may result in varying perception of the use of marijuana medically and recreationally. Further, the study only included English-speaking patients. Patients who speak other languages may also demonstrate these variations in geographical and cultural beliefs that may affect the perception of marijuana. This study was also conducted with cancer patients who may have a different symptom profile compared with patients with other conditions. In addition, the patients who were enrolled in the study were seen in palliative care centers and who may have a more distinct symptom distress profile than other cancer patients. Patients with less symptom burden may have a different attitude regarding marijuana use and may look less favorably at its potential benefits. This study was able to provide a snapshot but we recommend further research to understand universal factors that can influence patients' perceptions of the benefits and risks involved in marijuana use.

In summary, cancer patients from both legalized and nonlegalized states showed strong support for legalization of marijuana for medical purposes and strong belief in its medical use. The support for legalization for medical use was significantly higher than legalization for recreational use. Patients who are younger, had worse fatigue, appetite, and anxiety demonstrated higher support for MM. Further research is needed to understand factors that affect patients' attitudes and beliefs in use of MM as well as its potential uses and toxicities.

\section{Acknowledgment}

Further administrative, technical, and material support is provided by Janet Williams, Vera dela Cruz, Edrea Gonzales, Marie Jones, Julio Allo, and Brenda Noggy. Patient accrual support is provided by Hilda Cantu, Wendy Beers, and Michael McMahon.

\section{Author Disclosure Statement}

No competing financial interests exist.

The abstract with partial findings was presented as a poster presentation at the 2018 Palliative Care in Oncology 
Symposium on November 16-17, 2018 in San Diego, California. The abstract was also accepted as an e-poster at the 2019 Multinational Association of Supportive Care in Cancer Annual Meeting to be held on June 21-23, 2019. We have not otherwise published the findings of this study elsewhere. There is no specific funding for this work.

\section{Supplementary Material}

Supplementary Appendix A

\section{References}

1. Anderson L. Marijuana: Effects, medical uses and legalization. https://www.drugs.com/illicit/marijuana.html. (Last accessed May 15, 2019).

2. Cannabis and Cannabinoids $\left(\mathrm{PDQ}^{\circledR}\right)$ - Health Professional Version. https://www.cancer.gov/about-cancer/treatment/ cam/hp/cannabis-pdq. (Last accessed April 17, 2019).

3. Center for Behavioral Health Statistics and Quality: Behavioral health trends in the United States: Results from the 2014 National Survey on Drug Use and Health (HHS Publication No. SMA 15-4927, NSDUH Series H-50). 2015. www.samhsa.gov/data/sites/default/files/NSDUH-FRR1-2014/ NSDUH-FRR1-2014.pdf. (Last accessed April 17, 2019).

4. Center for Behavioral Health Statistics and Quality: Risk and protective factors and initiation of substance use: Results from the 2014 National Survey on Drug Use and Health. 2015. www.samhsa.gov/data/sites/default/files/NSDUH-DRFRR4-2014rev/NSDUH-DR-FRR4-2014.pdf. (Last accessed April 17, 2019).

5. Compton WM, Han B, Jones CM, et al.: Marijuana use and use disorders in adults in the USA, 2002-14: Analysis of annual cross-sectional surveys. Lancet Psychiatry 2016;3: 954-964.

6. Hughes A, Lipari RN, Williams MR: Marijuana use and perceived risk of harm from marijuana use varies within and across states. The CBHSQ Report. Rockville, MD: Substance Abuse and Mental Health Services Administration (US), July 26, 2016.

7. 33 Legal Medical Marijuana States and DC Laws, Fees, and Possession Limits. https://medicalmarijuana.procon.org/ view.resource.php?resourceID=000881. (Last accessed April 17, 2019).

8. 17 States with Laws Specifically about Legal Cannabidiol (CBD) (as of May 8, 2018). https://medicalmarijuana.procon .org/view.resource.php?resourceID=006473. (Last accessed April 17, 2019).

9. Abrams DI, Couey P, Shade SB, et al.: Cannabinoid-opioid interaction in chronic pain. Clin Pharmacol Ther 2011;90: 844-851.

10. Duran M, Pérez E, Abanades S, et al.: Preliminary efficacy and safety of an oromucosal standardized cannabis extract in chemotherapy-induced nausea and vomiting. Br J Clin Pharmacol 2010;70:656-663.

11. Guzmán M: Cannabinoids: Potential anticancer agents. Nat Rev Cancer 2003;3:745-755.

12. The National Academies of Sciences, Engineering and Medicine: The Health Effects of Cannabis and Cannabinoids: The Current State of Evidence and Recommendations for Research. http://nationalacademies.org/hmd/Reports/ 2017/health-effects-of-cannabis-and-cannabinoids.aspx. (Last accessed April 17, 2019).
13. Australian Government Department of Health Therapeutic Goods Administration: Medical cannabis-guidance documents. https://www.tga.gov.au/medicinal-cannabis-guidancedocuments. (Last accessed April 17, 2019).

14. Davis MP: Cannabinoids for symptom management and cancer therapy: The evidence. J Natl Compr Canc Netw 2016;14:915-922.

15. Steele G, Ameson T, Zylla D: A comprehensive review of cannabis in patients with cancer: Availability in the USA, general efficacy, and safety. Curr Oncol Rep 2019; 21:10.

16. Adler JN, Colbert JA: Medicinal use of marijuana-Polling results. N Engl J Med 2013;368;e30.

17. Consroe P, Musty R, Rein J, et al.: The perceived effects of smoked cannabis on patients with multiple sclerosis. Eur Neurol 1997;38:44-48.

18. Ware MA, Doyle CR, Woods R, et al.: Cannabis use for chronic non-cancer pain: Results of a prospective survey. Pain 2003;102:211-216.

19. Furler MD, Einarson TR, Millson M, et al.: Medicinal and recreational marijuana use by patients infected with HIV. AIDS Patient Care STDS 2004;18:215-228.

20. Westfall RE, Janssen PA, Lucas P, Capler R: Survey of medicinal cannabis use among childbearing women: Patterns of its use in pregnancy and retroactive self-assessment of its efficacy against 'morning sickness'. Complement Ther Clin Pract 2006;12:27-33.

21. Fiz J, Duran M, Capella D, et al.: Cannabis use in patients with fibromyalgia: Effect on symptoms relief and healthrelated quality of life. PLoS One 2011;6:e18440.

22. Pergam SA, Woodfield MC, Lee CM, et al.: Cannabis use among patients at a comprehensive cancer center in a state with legalized medicinal and recreational use. Cancer 2017; 123:4488-4497.

23. Arizona Department of Health Services: Medical marijuana. http://azdhs.gov/licensing/medical-marijuana/index.php. (Last accessed April 17, 2019).

24. Arthur J, Tanco K, Park M, et al.: Personalized pain goal as an outcome measure in routine cancer pain assessment. J Pain Symptom Manage 2018;56:80-87.

25. Dev R, Parsons HA, Palla S, et al.: Undocumented alcoholism and its correlation with tobacco and illegal drug use in advanced cancer patients. Cancer 2011;117:45514556.

26. Kwon JH, Tanco K, Park JC, et al.: Frequency, predictors, and medical record documentation of chemical coping among advanced cancer patients. Oncologist 2015;20:692-697.

27. Bruera E, Kuehn N, Miller MJ, et al.: The Edmonton Symptom Assessment System (ESAS): A simple method for the assessment of palliative care patients. J Palliat Care 1991;7:6-9.

28. Hui D, Bruera E: The Edmonton Symptom Assessment System 25 years later: Past, present, and future developments. J Pain Symptom Manage 2017;53:630-643.

29. Delgado-Guay MO, Chisholm G, Williams J, et al.: Frequency, intensity, and correlates of spiritual pain in advanced cancer patients assessed in a supportive/palliative care clinic. Palliat Support Care 2016;14:341-348.

30. Dugan E, Trachtenberg F, Hall MA: Development of abbreviated measures to assess patient trust in a physician, a health insurer, and the medical profession. BMC Health Serv Res 2005;5:64.

31. Zigmond AS, Snaith RP: The Hospital Anxiety and Depression Scale. Acta Psychiatr Scand 1983;67:361-370. 
32. Plante TG, Boccaccini M: The Santa Clara Strength of Religious Faith Questionnaire. Pastoral Psychol 1997;45: 375-387.

33. Sherman AC, Simonton S, Adams DC, et al.: Measuring religious faith in cancer patients: Reliability and construct validity of the Santa Clara Strength of Religious Faith questionnaire. Psychooncology 2001;10:436-443.

34. Plante TG, Vallaeys C, Sherman AC, Wallston KA: The development of a brief version of the Santa Clara Strength of Religious Faith Questionnaire. Pastoral Psychol 2002;50: 359-368.

35. Luckett T, Phillips J, Lintzeris N, et al.: Clinical trials of medicinal cannabis for appetite-related symptoms from advanced cancer: A survey of preferences, attitudes and beliefs among patients willing to consider participation. Intern Med J 2016;46:1269-1275.

36. Harris D, Jones RT, Shank R, et al.: Self-reported marijuana effects and characteristics of 100 San Francisco medical marijuana club members. J Addict Dis 2000;19: 89-103.

37. Aggarwal SK, Carter GT, Sullivan MD, et al.: Prospectively surveying health-related quality of life and symptom relief in a lot-based sample of medical cannabisusing patients in urban Washington State reveals managed chronic illness and debility. Am J Hosp Palliat Care 2013; 30:523-531.

38. Reiman A: Medical cannabis patients: Patient profiles and health care utilization patterns. Complement Health Pract Rev 2007;12:31-50.

39. Reiman A: Cannabis as a substitute for alcohol and other drugs. Harm Reduct J 2009;6:35.

40. World Health Organization: The ASSIST project-Alcohol, Smoking and Substance Involvement Screening Test. WHOASSIST V3.0. www.who.int/substance_abuse/activities/ assist/en. (Last accessed April 17, 2019).

41. The National Drug and Alcohol Research Centre, University of South Wales, Australia: Medical Cannabis Survey of the University of New South Wales (Australia). www.cannabismed.org/english/australia_questionnaire.pdf. (Last accessed April 17, 2019).

42. Access 420 Medical Services: Patient Questionnaire. www .access420medical.net/images/patient-info-packet.pdf. (Last accessed April 17, 2019).

43. Carlini BH, Garrett SB, Carter GT: Medicinal Cannabis: A survey among health care providers in Washington State. Am J Hosp Palliat Care 2017;34:85-91.

44. Saadeh CE, Rustem DR: Medical marijuana use in a community cancer center. J Oncol Pract 2018;14:e566-e578.
45. Zhang $\mathrm{H}$, Xie $\mathrm{M}$, Archibald SD, et al.: Association of marijuana use with psychosocial and quality of life outcomes among patients with head and neck cancer. JAMA Otolaryngol Head Neck Surg 2018;144:1017-1022.

46. Campbell G, Hall WD, Peacock A, et al.: Effect of cannabis use in people with chronic non-cancer pain prescribed opioids: Findings from a 4-year prospective cohort study. Lancet Public Health 2018;3:e341-e350.

47. Braun IM, Wright A, Peteet J, et al.: Medical oncologists' beliefs, practices and knowledge regarding marijuana used therapeutically: A nationally-representative survey study. J Clin Oncol 2018;36:1957-1962.

48. Wen H, Hockenberry JM: Association of medical and adult-use marijuana laws with opioid prescribing for Medicaid enrollees. JAMA Intern Med 2018;178:673-679.

49. Bradford AC, Bradford WD, Abraham A, Bagwell Adams G: Association between US state medical cannabis laws and opioid prescribing in the Medicare Part D population. JAMA Intern Med 2018;178:667-672.

50. Bradford AC, Bradford WD: Medical marijuana laws may be associated with a decline in the number of prescriptions for medicaid enrollees. Health Aff (Millwood) 2017;36: 945-951.

51. Powell D, Pacula RL, Jacobson M: Do medical marijuana laws reduce addictions and deaths related to pain killers? J Health Econ 2018;58:29-42.

52. Liang D, Bao Y, Wallace M, et al.: Medical cannabis legalization and opioid prescriptions: Evidence on US Medicaid enrollees during 1993-2014. Addiction 2018;113: 2060-2070.

53. Bauer FL, Donahoo WT, Hollis HW Jr, et al.: Marijuana's influence on pain scores, initial weight loss, and other bariatric surgical outcomes. Perm J 2018;22:18-002.

54. Schauer GL, King BA, Bunnell RE, et al.: Toking, vaping, and eating for health or fun: Marijuana use patterns in adults, U.S., 2014. Am J Prev Med 2016;50:1-8.

Address correspondence to: Kimberson Tanco, MD

Department of Palliative, Rehabilitation, and Integrative Medicine

University of Texas MD Anderson Cancer Center 1515 Holcombe Boulevard, Unit 1414 Houston, TX 77030

E-mail: kctanco@mdanderson.org 